\title{
A FUNÇÃO SOCIAL DA EMPRESA DE TELECOMUNICAÇÃO E A PRESTAÇÃO DE SERVIÇOS NA RELAÇÃO DE CONSUMO DE TELE ATENDIMENTO
}

\author{
Alessandra Harumi Sakai dos Santos ${ }^{1}$, Carla Bonomo ${ }^{2}$, Pedro Teófilo de Sá ${ }^{3}$ \\ ${ }^{1}$ Discente do curso de Administração - Universidade do Oeste Paulista - UNOESTE. ${ }^{2}$ Docente do curso de Direito - \\ Universidade Estadual de Londrina - UEL. ${ }^{3}$ Docente do curso de Administração - Universidade do Oeste Paulista - \\ UNOESTE. E-mail: teofilopp@gmail.com
}

\section{RESUMO}

O objetivo deste estudo é analisar a aplicação da função social da empresa de telecomunicação na relação de consumo decorrente dos serviços tele atendimento. Pautado no código de defesa do consumidor se verificará a formação da relação de consumo e a aplicação da função social, por meio das evidências disponíveis na literatura. A evolução histórica da empresa, desde o século XIX até a atualidade, aponta transformações rumo à função social nas organizações. Isso reflete sobre a empresa, o tele atendimento e a relação de consumo. Na modernidade, as mudanças são inevitáveis, por isso, a proatividade do gestor é fundamental nos serviços de tele atendimento, para que se possa manter o equilíbrio na relação consumo, cumprindo, assim, a função social. Portanto, as evidências disponíveis demonstram que a predisposição proativa do administrador é fator determinante da aplicação da função social da empresa de telecomunicação, na relação de consumo no tele atendimento.

Palavras-chave: Função social, tele atendimento, telecomunicação e relação de consumo.

\section{INTRODUÇÃO E OBJETIVO}

A evolução histórica da empresa, desde o século XIX até a atualidade, aponta transformações rumo a uma nova realidade, a da função social nas organizações. A inter-relação dos princípios que norteiam as organizações conduz ao da função social da empresa, o que leva ao equilíbrio entre o lucro e a dita função, visando valorizar o ser humano, um ser hermenêutico e de possibilidades. Nesse contexto o código de defesa do consumidor surgiu para assegurar o equilíbrio da relação consumerista nas organizações.

A globalização e as transformações atuais fizeram com que as organizações mudassem a forma de operar, principalmente no que diz respeito ao tele atendimento. $E$ ainda, trouxe novas leis, a exemplo do direito do consumidor, que estabelece que o consumidor ${ }^{1}$ é considerado vulnerável, de forma que o Estado intervém nas relações de consumo, coibindo práticas abusivas contra o consumidor, para equilibrar a relação de consumo.

Diante disso, o objetivo deste estudo é analisar a aplicação da função social da empresa de telecomunicação na relação de consumo decorrente dos serviços tele atendimento.

\footnotetext{
${ }^{1}$ Pessoa física ou jurídica que adquire ou utiliza produtos ou serviços como destinatário final. O consumidor é aquele subordinado às condições e interesses impostos pelo titular dos bens ou serviços no atendimento a suas necessidades de consumo. CF art. $2 \stackrel{\circ}{\text { do }}$ CDC. 


\section{METODOLOGIA}

A pesquisa cientifica deve ser composta por procedimentos sistemáticos, e conforme Rampazzo, (2005, p. 73) "a metodologia explica o tipo de pesquisa, se é apenas bibliográfica ou documental $[\ldots]$ ". O termo metodologia pode indicar também o referencial teórico, ou quadro de referencia. Deste modo esta pesquisa se baseia em bibliografias especializadas como livros, revistas monografias, artigos científicos e internet.

\section{RESULTADOS}

As evidências disponíveis demonstram que a empresa está inserida numa nova realidade que desencadeia a necessidade da aplicação da função social pautada no desenvolvimento da lucratividade conexo à manutenção do bem-estar da coletividade atendida na relação de consumo do serviço de tele atendimento na telecomunicação. Esse fenômeno é dependente da proatividade do administrador em busca da detecção e resolução de problemas, permitindo-o ao cumprimento tanto da função lucrativa como social. Inevitavelmente, ocorre o respeito aos direitos básicos do consumidor garantidos pelo código de defesa do consumidor com relação aos serviços de tele atendimento nas empresas de telecomunicação.

\section{DISCUSSÃO}

Para o estudo da aplicação da função social, objeto deste trabalho é necessário uma abordagem teórica da empresa, da função social, da relação de consumo e do serviço de telecomunicação.

A nova realidade empresarial no seguimento de telefonia no Brasil tem sido marcada por promessas de investimentos tecnológicos do setor, atendendo às regras impostas pela Agência Nacional de Telecomunicação, a NATEL e pelo código de defesa do consumidor, com o intuito de dar efetividade ao serviço de tele atendimento, na relação de consumo.

A nova visão da empresa, do século XXI, passa por um momento de conexão entre as regras de controle e a finalidade social e lucrativa.

O conceito de empresa conforme Palaia (2004, p. 172) é "o conjunto dos fatores de produção $^{2}$ que, sob a direção de uma pessoa, o empresário ${ }^{3}$, é organizado em vista da produção de bens e serviços para o mercado". Observa-se que o significado de empresa é muito abrangente, e

\footnotetext{
${ }^{2}$ Fatores de produção são o capital( aplicados na empresa pode ser transformado em prédios, terrenos, máquinas, instalações, ferramentas, móveis e utensílios, etc.) e o trabalho(atividade do ser humano dedicada a empresa).

3 “Considera-se empresário quem exerce profissionalmente atividade econômica organizada para a produção ou circulação de bens ou serviços para o mercado, com intuito de lucro, com exceção das atividades imobiliárias e das profissões intelectuais de natureza cientifica, literária ou artistica"(PALAIA, 2004, pg. 173). Cf art. 966 Código Civil.
} 
que necessita de organização intelectual, para ser bem sucedida, não sendo suficiente apenas a produção e circulação de riquezas. É preciso o cuidado com o papel social que a organização deve desenvolver, aliado ao respeito ao consumidor.

A empresa no século XIX era visto como uma entidade econômica que acima de tudo visava o lucro, não importando as demais implicações ou problemas futuros relacionados ao cliente, e muito menos com o aspecto social que, hoje, é um dos alicerces fundamentais da empresa. As tecnologias influenciaram a visão conceitual da empresa.

A nova visão da empresa, do século XXI, passa por um momento de conexão entre as regras de controle e a finalidade social e lucrativa.

Na modernidade, observa-se que o administrador do seguimento de telecomunicação, deve agir com muita cautela, adotando uma postura proativa ${ }^{4}$, visando minimizar o sofrimento do consumidor pela busca da satisfação do problema, quando aciona o serviço de tele atendimento. Para isso, pode valer-se de meios midiáticos de informação e telefonia eletrônica e ou ainda, contatos virtuais. Essas e outras novas tecnologias presentes no século XXI, têm feito com que as empresas do seguimento procurem uma maior satisfação dos serviços no atendimento e na funcionalidade dos serviços, pautados na ampla interconectividade através das evoluções das telecomunicações e a diversificação da comunicação, sem perder o foco da função social.

Conforme Barbulho (2001, p.66), “As pessoas possuem hábitos, temperamentos, grau de instrução e educação diferentes umas das outras e os prestadores de serviços deverão estar preparados para tomar atitudes adequadas para cada tipo de pessoa".

Observa-se que a organização tem de conviver com a sua pretensão lucrativa e com a execução da função social, por isso é necessário muita cautela ao lidar com uma diversidade de pessoas no serviço de tele atendimento.

Função social da empresa é um termo que vem sendo utilizado constantemente na seara empresarial, como forma de limitar algumas ações do empresário que, modernamente, não pode perseguir apenas o lucro. Assim é imprescindível compreender o assunto no contexto do serviço de tele atendimento, pois o termo função social leva à ideia de ação com escopo coletivo voltado para o ser hermenêutico. ${ }^{5}$

\footnotetext{
${ }^{4}$ Prever uma situação e agir antes dela acontecer, estar atento a sua volta, ter raciocínio rápido, ter ação.

${ }^{5}$ A hermenêutica auxilia na compreensão da realidade como objeto de interpretação do momento em que está sendo utilizada, com isso busca o sentido sobre o ser humano. Essa reflexão abre caminho para a construção de um sentido humano para o direito, voltado para a prática interpretativa. 
Para melhor caracterizar o que se denomina por função social socorre-se da lição de Tomasetti Junior (1996, p.221) que a define como [...] "expressão sintetizante de valores, econômicos e não econômicos assimilados pelo ordenamento jurídico".

Nota-se que o sistema jurídico recepciona a função e social e determina a busca não apenas do fim econômico, mas também do atendimento ao consumidor, visando a excelência o equilíbrio da relação de consumo.

A função social deita suas raízes na função social da propriedade, visto que no estado liberal, ela era exclusivamente daquele que fazia seu investimento financeiro para a criação de uma organização, em busca da geração do lucro a qualquer custo. Todavia, o século XXI não é suficiente, é preciso respeito aos direitos básicos do consumidor, dentre eles o de informação e o equilíbrio da relação de consumo.

Dita função social impulsiona o progresso material da organização, considerando a valorização do humanismo e da criatividade, observadas através das conquistas oriundas do conhecimento humano (LOSSO, 2008, p.108). Essa nova formatação do direito do século XXI, abandonou o individualismo primando pelo aspecto social, inclusive nas organizações, principalmente nos serviços de tele atendimento, onde se executa o direito a comunicação.

Nesse aspecto a ação da organização deverá se pautada numa postura ética (BITTAR, 2005, p. 403), fato que leva à função social.

No serviço de tele atendimento, o respeito aos direitos básicos do consumidor, dentre eles o da informação caminhará rumo à função social.

O código de defesa do consumidor, traz a formação da relação de consumo em seu bojo, com a finalidade específica de fixar limites às partes, o fornecedor e o consumidor. Com isso, visa equilibrar a relação de consumo, para tanto considera o consumidor vulnerável ${ }^{6}$ e hipossuficiente ${ }^{7}$, afim de protegê-lo contra os abusos do fornecedor.

Ao equilibrar a relação de consumo impõe ao fornecedor, o de dever de informar ao consumidor acerca do serviço ou produto, objeto da relação consumerista.

Segundo Almeida $(2009$, p.1), as relações de consumo são bilaterais, onde, numa ponta, está o fornecedor, que pode ser o fabricante, produtor, importador, comerciante; e prestador de serviço, ou seja, aquele que se dispõe a fornecer bens e serviços a terceiro. $E$, na outra ponta, o

\footnotetext{
${ }^{6}$ Vulnerável, por ser a parte mais fraca na relação de consumo.

${ }^{7}$ Hipossuficiente, por possuir desconhecimento técnico do produto ou serviço, de suas oportunidades, dos aspectos que geram o acidente de consumo e dano, das características do vício etc.
} 
consumidor, aquele subordinado às condições e interesses impostos pelo titular dos bens ou serviços no atendimento a suas necessidades de consumo.

Observa-se que é a partir da bilateralidade e da manifestação da vontade expressa pelas partes que passa a existir a relação de consumo, com a qual a organização deverá gerir seus desdobramentos.

Para garantir a harmonia da relação consumerista contratual, as partes precisam respeitar a boa fé, que está prevista no Código de Defesa do Consumidor, no art. $4^{\circ}$ inciso $1 \mathrm{II}^{8}$, já que as partes devem agir com lealdade e segurança recíprocas (OLIVEIRA, 2002, p.23).

A boa fé é um dos elementos fundamentais, para demonstrar e garantir a lealdade e o respeito das partes contratantes, assegurando, dessa forma, o equilíbrio na relação de consumo que contará com a atuação proativa do administrador na organização, mesmo quando se tratar de tele atendimento.

No código de defesa do consumidor encontram-se normas inspiradas no princípio da informação, mais explicitamente nos artigos. 4으, inciso $\mathrm{IV}^{9}$, e 6으, inciso $\mathrm{II}^{10}$. De acordo com esse princípio a organização do setor de telecomunicação, especificamente pelo serviço de tele atendimento deve fornecer informação ${ }^{11}$ adequada, clara e honesta em toda relação de consumo, em busca do equilíbrio.

Dos tempos antigos até agora, grandes transformações marcaram o cenários das telecomunicações. Nos dias de hoje é fundamental uma comunicação funcional, segura, a exemplo da energia elétrica, água, gás, transporte, educação, etc. (LOSSO, 2008 p. 112), já que todos são serviços fundamentais.

Diante disso, observa-se que as empresas de telecomunicação têm liberdade para prestar os serviços, no entanto, são controladas e fiscalizadas pelo poder estatal, conforme o art. $6^{\circ 12}$ da Lei Geral das Telecomunicações.

\footnotetext{
${ }^{8}$ Art. $4^{\circ} \ldots$

III- harmonização dos interesses dos participantes das relações de consumo e compatibilização da proteção do consumidor com a necessidade de desenvolvimento econômico e tecnológico, de modo a viabilizar os princípios nos quais se funda a ordem econômica (art.170, da CF), sempre com base na boa fé e equilíbrio nas relações entre consumidores e fornecedores.

${ }^{9}$ VI- Educação e informação de fornecedores e consumidores, quanto aos seus direitos e deveres, com vista a melhoria do mercado de consumo.

${ }^{10}$ III- A informação adequada e clara sobre os diferentes produtos e serviços, com especificação correta de quantidade, características, composição, qualidade e preço, bem como sobre os riscos que apresentem.

${ }^{11} \mathrm{O}$ fornecedor tem dever de informar enquanto o consumidor o direito de receber todas as informações sobre o bem ou serviço adquirido. (LEITE,2002, p.102).

${ }^{12}$ Art. 60 - Os serviços de telecomunicações serão organizados com base no principio da livre, ampla e justa competição entre todas as prestadoras, devendo o poder público atuar para propiciá-la bem como para corrigir os efeitos da competição imperfeita e reprimir as infrações de ordem econômica.
} 
A exigência na qualidade da prestação de serviços, fez com que o Estado passasse de prestador para regulador (LOSSO, 2008, p. 124), estabelecendo uma obrigação das empresas ao fornecerem serviço de teleatendimento.

Um serviço para ter qualidade precisa atender a finalidade para qual foi destinado (BARBULHO, 2001, p. 24). Então, nesse cenário, o serviço de tele atendimento deve atender aos anseios, no mínimo, de informação adequada, clara e precisa solicitada pelo consumidor, no menor tempo possível.

Conforme Barbulho (2001, p. 27), para obter um bom atendimento, as pessoas executantes devem ser treinadas e seguir as instruções recebidas.

Cada atendimento é único e varia de pessoa para pessoa, todas requerem respeito e resolução dos problemas. É nesse momento, que o gestor, conhecendo os desdobramentos da decisão, adota uma postura proativa para a resolução do problema (BARBULHO, 2001, p.76).

Nesse contexto a organização deve identificar, reconhecer e gerir a relação de consumo do serviço de tele atendimento, procurando atender às reclamações minimizando o tempo de espera e com cautelas quanto o tempo despendido para o atendimento e para a resolução do problema.

Desse modo, o administrador deve atender e informar eficazmente a solicitação do consumidor em respeito às normas das agências reguladoras, a ANATEL- Agencia nacional de telecomunicações e do código consumerista.

A combinação do conhecimento aplicada às tarefas da organização, modernizaram a forma de atendimento ao consumidor e a realidade organizacional, pois destaca a era das pessoas, já que todos se utilizam da tecnologia aplicada à informação e à comunicação, como estratégia para o caminho do sucesso, profissional ou pessoal.

Desse modo, o administrador da organização do ramo da telecomunicação, fornecedora do serviço através do tele atendimento, deverá conhecer os principais aspectos legais consumeristas, dentre eles o da informação. A partir de então, com uma postura proativa e se torna mais hábil para o processo de tomada de decisão e resolução dos problemas de modo a manter equilibrada a relação de consumo.

\section{CONSIDERAÇÕES FINAIS}

A empresa, na modernidade, não pode não pode mais existir fundamentada apenas na busca pela lucratividade, precisa se inserir na realidade social empresarial, que parte da ideia da 
aplicação da função social pautada no desenvolvimento da lucratividade conexo à manutenção do bem-estar da coletividade.

A aplicação da função social, caracterizada, sobretudo, pela boa-fé e bem-estar da coletividade, deve estar intimamente relacionada às perspectivas de lucratividade na prestação de serviços na relação de consumo de tele atendimento das empresas de telecomunicação.

O código de defesa do consumidor prevê a formação da relação de consumo com a finalidade específica de fixar limites às partes, o fornecedor e o consumidor. O objetivo principal é manter o equilibrar da relação de consumo. Para tanto, considera o consumidor vulnerável e hipossuficiente, afim de protegê-lo contra os abusos do fornecedor.

Ao equilibrar a relação de consumo impõe ao fornecedor, o de dever de informar ao consumidor acerca do serviço ou produto, objeto da relação consumerista.

A relação de consumo está presente no serviço de tele atendimento, na telecomunicação e por isso deve atender ao consumidor, no tele atendimento pautado na realidade contemporânea.

Nota-se pelas evidências literárias que este século não prestigia a prestação de serviços de tele atendimento pela vertente empresarial da busca exclusiva do lucro do século passado.

Esse fenômeno é dependente da proatividade do administrador que também deve estar atento aos aspectos legais das empresas de telecomunicações, incluindo o código de defesa do consumidor.

É preciso que o administrador esteja capacitado para a detecção de potenciais problemas de modo que possam ser prontamente apresentados com postura de respeito e eficiência na condução e solução dos respectivos problemas. As ações proativas devem ser executadas com supedâneo ético e cumpridoras à função social da empresa. Muito possivelmente, isso proporcionará o surgimento da confiabilidade do usuário, devido ao fato de o consumidor receber papel de relevância singular na relação de consumo e no sistema econômico e social brasileiro.

Desta forma, o gestor estará pautado na boa fé contratual, reconhecendo as determinações de respeito e o cumprimento aos direitos básicos do consumidor, primando pelo equilíbrio na relação contratual consumerista.

Portanto, as evidências disponíveis demonstram que a proatividade do administrador é fator determinante para a aplicação função social no serviço de tele atendimento nas empresas de telecomunicação, de modo a atender aos direitos básicos de informação contemplados no código de defesa do consumidor. 


\section{REFERÊNCIAS}

ALMEIDA, J. B. Manual de Direito do Consumidor. 3. ed. rev. São Paulo: Saraiva, 2009.

BARBULHO, E. Excelência na prestação de serviço: Guia para desenvolvimento do profissional autônomo e para o sucesso das empresas. São Paulo: Madras Editora LTDA, 2001.

BITTAR, E. C.B. Curso de ética jurídica: ética geral e profissional. 3.ed. ver. São Paulo: Saraiva, 2005.

BANNWART JÚNIOR, C. J. et al. Direito e inovação: Estudos críticos sobre Estado, Empresa e Sociedade. Juiz de Fora: UFJF, 2013.

LANGARO, L. L. Curso de Deontologia jurídica. 2. ed. atual. São Paulo: Saraiva, 1996.

LEITE, R. B. Introdução ao Direito do Consumidor: os Direitos do Consumidor e a aplicação do Código de Defesa do Consumidor. São Paulo: LTR, 2002.

LOSSO E. Atividade empresarial de telefonia de radiofrequência e inclusão social. Curitiba: LTL, 2008.

OLIVEIRA, J. C. Código de Defesa do Consumidor: doutrina, jurisprudência e legislação complementar - 3. ed.- São Paulo: Lemos e Cruz, 2002.

PALAIA, N. Noções essenciais de Direito. 2. ed. São Paulo: Saraiva, 2004.

RAMPAZZO, L. Metodologia Cientifica: para alunos dos cursos de graduação e pos- graduação. 2. ed. São Paulo: Edições Loyola, 2004.

SODRÉ, M. O monopólio da fala: função e linguagem da televisão no Brasil. Petrópolis: Vozes, 1984.

TOMASETTI JUNIOR, A. Jurisprudência Comentada. Revista dos Tribunais. São Paulo, ano 85, v.723,p.221, jan.1996. 